\title{
UNIVERZALNI ADAPTER ZA BELEŽENJE MERENJA KOD ELEKTRONSKIH MERNIH INSTRUMENATA
}

\author{
Szegedi Attila ${ }^{1}$ \\ Szegedi Mihály ${ }^{2}$ \\ Danijel Kukaras ${ }^{3}$
}

УДК: 621.317

DOI:10.14415/konferencijaGFS 2015.036

Rezime: U radu je prikazan razvoj univerzalnog adaptera za elektronske merne instrumente: nonijuse, komparatere $i$ merne trake koji se koriste za ispitivanje građevinskih materijala $i$ konstrukcija. Prototip adaptera je realizovan u kratkom vremenu i u prvoj fazi radi sa 8 nonijusa. U toku razvoja i praktične primene došlo je do zaključka o daljem razvoju adaptera koji je postao i deo projekta koji je prihvaćen i na svetskom konkursu za razvoj i primenu elektronskih instrumenata.

Ključne reči: elektronski merni instrumenti, adapter za pretvaranje signala, ispitivanje građevinskih materijala i konstrukcija

\section{UVOD}

U sklopu završnih radova na diplomskim i postdiplomskim studijama Gađevinskog fakulteta Subotica, Univerziteta u Novom Sadu, u poslednje vreme je došlo do intenziviranja eksperimentalnih istraživanja na raznim konstruktivnim elementima i građevinskim materijalima. Eksperimenti se sprovode opterećivanjem do loma ili sa višestrukim ponovljanjima ispitivanja pod dejstvom različitih radnih opterećenja na istom elementu. Zajednički cilj kod svih eksperimenata je da se teži što tačnijem praćenju realnog ponašanja elemenata, deformacija i napona $u$ toku odvijanja eksperimenta. Ovo podrazumeva veliki broj mernih mesta i kontinualno praćenje i registrovanje (beleženje) svih promena. Ove promene se ponekad dešavaju u veoma kratkom vremenskom periodu te je praktično nemoguće da se manuelno registruju sve praćene (merene) vrednosti pri kojima je došlo do njih (na primer lom konstrukcije). Instrumenti koji su na raspolaganju za ova merenja su uglavnom kombinacije mehaničkih i elektronskih uređaja što podrazumeva kontinualno očitavanje i intenzivno praćenje i registrovanje vrednosti merenja. Postojeći elektronski instrumenti sa kojim

\footnotetext{
${ }^{1}$ Mr Szegedi Attila dipl.inž.građ.,Građevinski fakultet Subotica, Kozaračka 2a, tel:024/554-300, e-mail: atyi@gf.uns.ac.rs

${ }^{2}$ Szegedi Mihály, Strukovni inzinjer elektrotehnike i računarstva, specijalištičke studije mehatronike, VTŠ Subotica,Marka Oreškovića 16, e-mail: szegedimihaly1@gmail.com

${ }^{3}$ Prof.dr Danijel Kukaras, dipl.inž.građt, Građevinski fakultet Subotica, Kozaračka 2a, tel:024/554-300, e-mail: danijel.kukaras@gmail.com
} 
International conference

Contemporary achievements in civil engineering 24. April 2015. Subotica, SERBIA

raspolaže Građevinski fakultet Subotica mogu da vrše pojedinačna očitavanja ili je za složenije eksperimente potrebno je pozajmiti elektronsku mernu opremu imajući u vidu da je ona izuzetno skupa.

\section{DEFINISANJE I ANALIZA PROBLEMA}

Većina elektronskih mernih instrumenata koje poseduje Građevinski fakultet Subotica a koji su relativno cenovno pristupačni (nonijusi i komparateri) imaju i elektronski izlaz, međutim fabrički adapter za pretvaranje signala uglavnom daje se samo pojedinačno $i$ takođe je relativno skup. Dalji problem predstavlja da svaki proizvođač ima drugačiji elektronski priljučak (elektronski signal i oblik priključka).

Razvoj elektronike omogućava danas razvoj i izradu veoma efikasnih dodataka za rešavanje ovog problema i to po znatno povoljnijim troškovima izrade i eksploatacije.

U toku izrade jednog master rada [2] trebalo je da se izmere vrednosti deformacija i razvoj prslina u relativno kratkom vremenskom intervalu opterećivanja na šet armiranobetonskih greda. To je podrazumevalo očitavanje sa četiri merna mesta na malom prostoru što je dodatno otežavalo očitavanja. U toku priprema za eksperiment došlo se do zaključka na osnovu uvida u diplomski rad [3], da je modifikacijom adaptera obrađenog u tom radu, moguća realizacija jednog sličnog uređaja koji bi bio upotrebljen kod merenja sa nonijusima (Slika 1a), komparaterima a kasnije i mernim trakama.

\section{IZRADA PROTOTIPA I PRIMENA KOD ISPITIVANJA}

Definisanjem osnovnih parametara i ispitivanjem izlaznog signala nonijusa pristupilo se projektovanju adaptera, Slika $1 \mathrm{~b}$. U toku projektovanja identifikovani su i rešeni sledeći problemi

- broj ulaza je maksimalizovan na osam,

- utikači na instrumentu su prilagođeni svakodnevnom radu višestruko izdržljiviji i jednostavniji, pouzdaniji od fabričkih (i višestruko jednostavniji i jeftiniji u slučaju zamene),

- ulazi u adaper su standardni RJ-45 telefonski konektori,

- jednostavan način postavljanja osnovnih parametara na LCD panelu sa šest testera,

- priključak na računar preko USB priključka,

- izlazni rezultati se beleže na računaru (laptopu) direkto u otvorenu Excel datoteku sa tačnošću mernog instrumenta,

- priključeno kontinualno napajanje stabilizovanom jednosmernom strujom, interval merenja: 0,$5 ; 1,0 ; 2,0 ; 5,0 ; 10,0$ i 60,0 sekundi. 

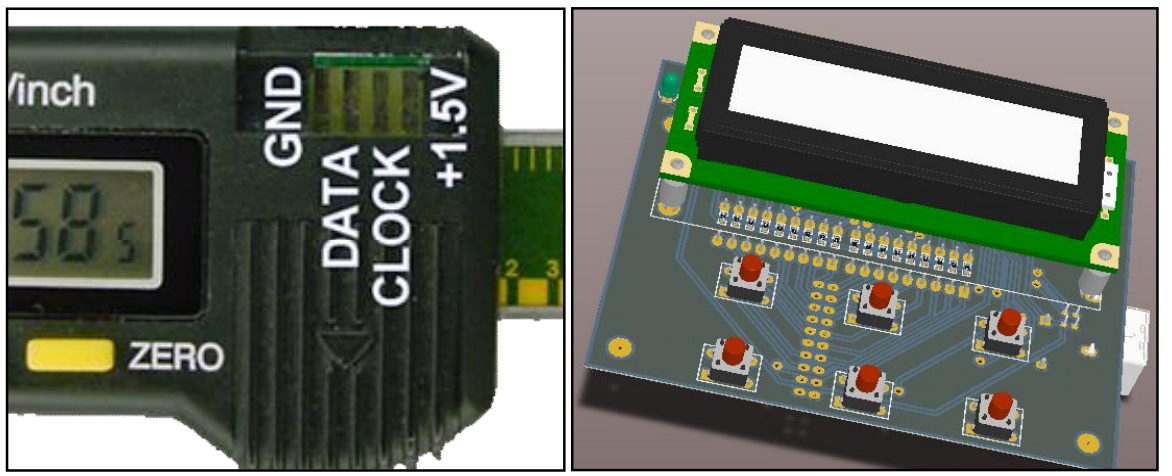

Slika 1. a) Digitalni nonijus sa elektronskim izlazom, b) 3D projektovanje matične ploče i rasporeda elektronskih komponenti adaptera

\section{OPIS ELEKTRONSKOG IZLAZA INSTRUMENTA}

Merni instrument (nonijus) poseduje elektronski izlaz sledećih karakteristika:

GND referentna tačka, napon napajanja $+1.5 \mathrm{~V}$, DATA izlaz za podatke, CLK izlaz za signal sata. Sam instrument, nonijus, podatke registruje sa sinhronom komunikacijom. Podatak se prikazuje u 4 bitnim blokovima BCD kodiranjem. Jedan paket sadrži 6 blokova. Prvi blok daje najmanji broj a 5. blok je najveći. Šesti blok daje predznak očitavanja.

\section{5. ŠEMA ELEKTRONIKE ADAPTERA}

Adapter je baziran na PIC18f4550 mikrokontroleru. Takt kontrolera je $32 \mathrm{MHz}$ i koristi standardnu USB-HID komunikacija sa računarom. Šema elektronike je data na Slici 2.

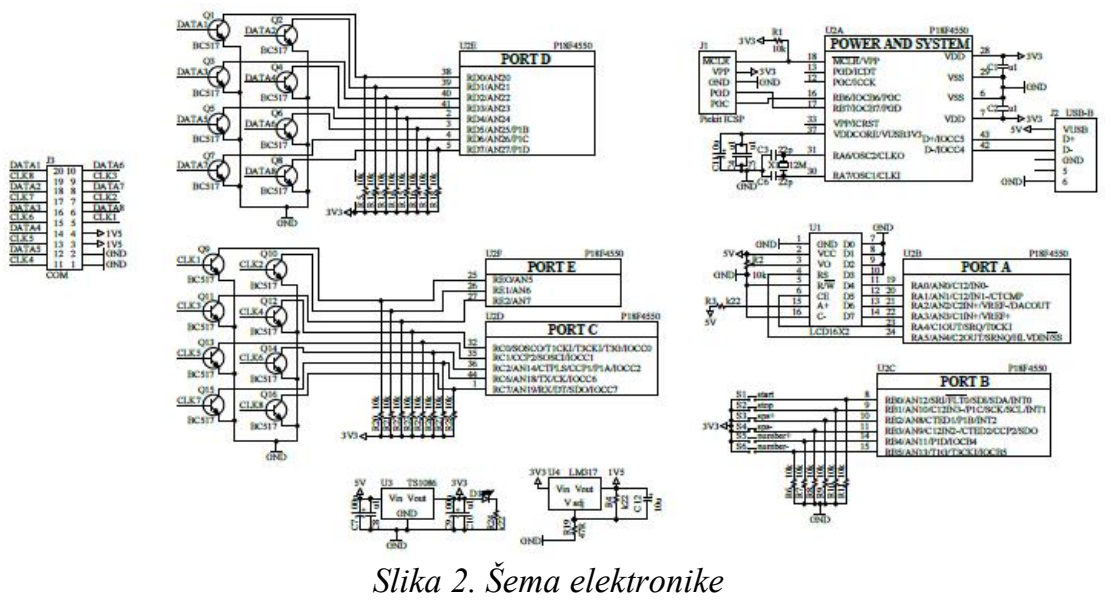




\section{$41^{\text {th }}$ ANNIVERSARY FACULTY OF CIVIL ENGINEERING SUBOTICA}

International conference

Contemporary achievements in civil engineering 24. April 2015. Subotica, SERBIA

Nonijusi zahtevaju stabilizovani napon, zato je potrebno koristiti spoljnu jedinicu napajanja (akumulator ili stabilizovani ispravljač). Radni napon mikrokontrolera je 3,3V i napojna jedinica je tipa TS1086. Napajanje i regulacija napona nonijusa se vrši kroz napojnu jedinicu tipa LM317. Radi lakšeg definisanja polaznih parametara adapter ima sopstveni LCD i šest mikroprekidača.

\section{PROGRAMSKA KONFIGURACIJA}

Prilikom praktične upotrebe konfiguracije (Slike 3, 4 i 5) trebalo je da se računa o sledećim parametrima: najmanje vreme na izlazu podataka kod nonijusa je $80 \mu$; podatke je trebalo uzimati sa kraćim vremenskim intevalom kako bi se isti mogli analizirati; s obzirom da korišćeni mikrokontroler nije dovoljno brz da paralelno očita podatke odjednom sa svih osam mernih mesta, očitavanje se vrši u grupama od po tri merna mesta; nonijusi šalju podatak svakih $150 \mathrm{~ms}$ i paket se ispisuje približno za $50 \mathrm{~ms}$, ukupno vreme očitavanja je na taj način oko 200 ms. Uzevši sve navedeno u obzir, ukupno pouzdano očitavanje za osam mernih mesta, kao najmanji vremenski interval ima $0,5 \mathrm{sec}$. Za potrebe korišćenja adaptera je izrađen i detaljan priručnik za upotrebu.
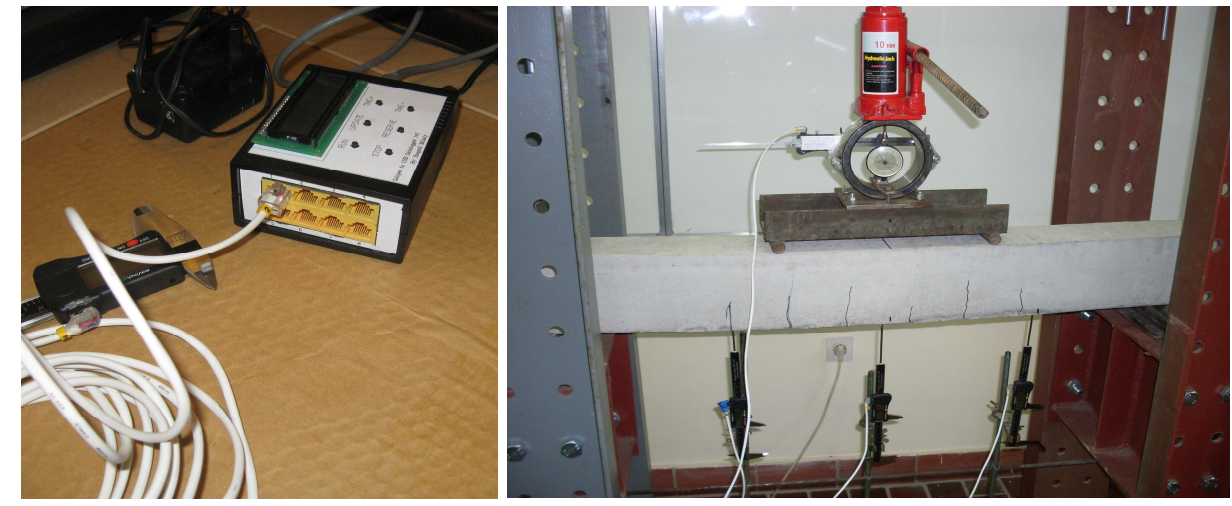

Slika 3. a) Prototip adaptera, b) Priključeni nonijusi na adapter u toku ispitivanja

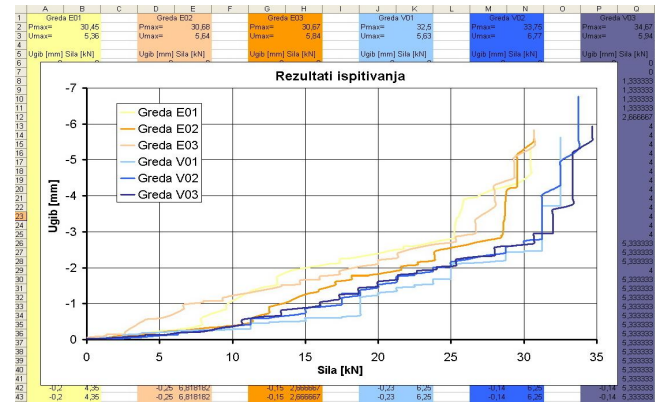

Slika 4. Prikaz rezultata u realnom vremenu 


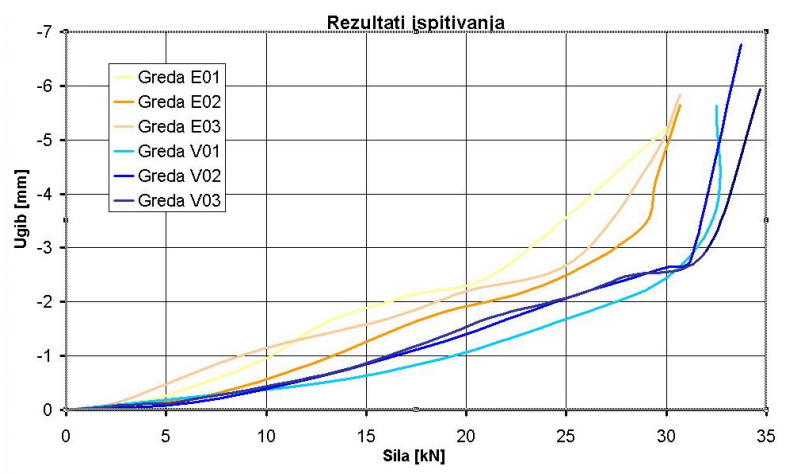

Slika 5. Interpolacija rezultata za ispitivane grede

\section{MOGUĆNOSTI DALJEG RAZVOJA}

U toku primene adaptera i analize rezultata došlo se do sledećih zaključaka u vezi sa za daljom mogućom primenom:

- potrebno je galvansko razdvajanje mernog instrumenta (mase) od adaptera,

- višestruko (multiplicirano) povećanje broja priključaka (detaljna analiza za sve vrste građevinskih objekata) bi znatno povećalu upotrebljivost adaptera odnosno potrebno je projektovanje tzv. koncentratora,

- razmotriti mogućnost priključenja više vrsta različitih mernih instrumenata jednovremeno (senzori temperature, mikrometri, merne trake, GPS senzori),

- predvideti automatsku kalibraciju mernih traka

- predvideti potpunu bežičnu komunikaciju sa pojedinim mernim mestima i sa računarom (wifi, onlajn),

- automatsko beleženje podataka na mikro SD memorijske kartice,

- mogućnost dugoročnog merenja uz nisku cenu,

- atestiranje adaptera.

Dodatna potvrda kvaliteta ovog uređaja je dobijena i kroz njegovo prihvatanje na svetskom konkursu za razvoj i primenu elektronskih instrumenata [1].

\section{ZAKLJUČAK}

Nesporno je da uređaji slični ovome postoje u svetu i da se oni masovno koriste u raznim granama privrede, međutim, uglavnom se radi uređajima koji su pravljeni samo za jednu namenu odnosno vrstu senzora. Osim toga, za naše prilike je najznačajnije da je nabavna cena ovih uređaja izuzetno velika. Imajući u vidu da je prikazani uređaj univerzalan, da se $u$ realnim ispitivanjima pokazao kao pouzdan i da je, pri tome, cenovno veoma pristupačan, smatramo da postoje svi preduslovi da se nastavi razvoj opisanog univerzalnog adaptera za ispitivanje konstrukcija i materijala i građevinarstvu. 


\section{LITERATURA}

[1] http://www.digilentdesigncontest.com/: Digilent Design Contest -international student hardware design competition open to students throughout the world

[2] Kőmüves Péter dipl.inž.građ.: Granična nosivost AB grednih nosača ojačanih čeličnim mikrovlaknima, Master rad, GF Subotica, 2013

[3] Szegedi Mihály: Hat szabadságfokú robotkar meghajtó elektronika tervezése és kivitelezése, Diplomamunka, VTŠ Subotica, 2013

[4] Segedi Mihalj: Projekat i izrada elekronskog upravljanja robotskom rukom sa šest stepeni slobode, Diplomski rad, VTŠ Subotica, 2013

\section{UNIVERSAL DATA LOGGER FOR ELECTRONIC MEASUREMENT DEVICES}

Summary: The paper presents a development of universal data logger for electronic measurement devices such as calipers, dial gauges and strain gauges which are used for testing of civil engineering materials and structures. Prototype of the data logger was developed in a short time and, in the first stage, it works with 8 calipers. During development and practical application a conclusion was made about the direction of future improvements for this data logger and this project was accepted in world wide competition for development and application of electronic devices in general.

Keywords: Electronic measurement devices, data logger, testing of civil engineering materials and structures 